Original Article

\title{
PREVALENCE OF SUBSTANCE USE DISORDERS AMONG PATIENTS OF ACCIDENT AND EMERGENCY DEPARTMENT OF A UNIVERSITY TEACHING HOSPITAL
}

\author{
Dapap D.D*, Audu M.D ${ }^{1}$, Obembe $A^{1}$, Goar $S^{1}$ \\ Quintessential Healthcare Centre Gold and Base junction, Rayfield ${ }^{*}$ and Department of Psychiatry, Jos University Teaching Hospital ${ }^{1}$, \\ Plateau State Nigeria
}

*Corresponding Author: Dr Dapap Delahik Datak, Quintessential Healthcare Centre Gold and Base junction, Rayfield Jos, P.M.B 2278, Jos Plateau State. E mail: ddapap@gmail.com

Received date: May $24^{\text {th }} 2018$, Accepted date: June $16^{\text {th }}$ 2018. Published date: June $30^{\text {th }} 2018$.

\begin{abstract}
Substance abuse and dependence are frequently encountered in emergency units of our hospitals, and it accounts for major health care problems frequently leading to accident and emergency department admission, though it is often missed or not diagnosed. The aim of this study was to estimate the prevalence of drug abuse and dependence among patients attending Accident and Emergency Hospitals and to determine the sociodemographic characteristics of these patients with substance use disorders. A total of 200 consented participants attending the accident and emergency unit of the hospital were recruited into the study consecutively over a 2-week period. They were screened for psychoactive substance use disorders (PSUD) with Alcohol, Smoking and Substance Involvement Screening Test (ASSIST) and urine drug test (UDT) in the first phase and the Mini International Neuropsychiatric Interview (MINI) Instrument was used to make definitive diagnosis in the second stage. The result revealed that the prevalence of substance use disorders was $19.0 \%$ (13.0\% for substance abuse and $6.0 \%$ for substance dependence). The study found that being male $(\mathrm{p}<0.001)$, widowed $(\mathrm{p} \leq 0.012)$, and Christian $(\mathrm{p}$ $\leq 0.006$ ) were associated with substance use disorders among patients presenting at accident and emergency units. The authors concluded that the prevalence of substance use disorders recorded in this study is higher compared to previous study conducted by Mustafa et al in Egypt with 11.5\%. The reason could be due to inclusion of biochemical test (urine drug test) in our screening, whereas only self-report questionnaires were used in their study.
\end{abstract}

Keywords: Drug, Jos, Neuropsychiatric, Substance Use Disorders, Test, Urine.

\section{Introduction}

Globally, substance use has become a major public health issue ${ }^{1}$. The United Nations Office for Drugs Control and Prevention estimated that between 155 and 250 million people or $3.5 \%$ to $5.7 \%$ of the world's population aged 15-64 has used drugs at least once in the last 12 months $^{2}$. For most of European and Asian countries, opiates continue to be the main drug of abuse and account for $62 \%$ of all treatment demands, resulting from substance use disorder. In South America, drug related treatment continues to be mainly linked to the use of cocaine which accounts for $59 \%$ of treatment demand. However, in Africa, the bulk of all treatment demand is linked to cannabis $(64 \%)$, resulting from substance use disorders. ${ }^{3}$
Psychoactive substance use cuts across all the geopolitical zones in Nigeria $^{4}$, and is increasing especially in adolescents. ${ }^{5}$ A recent national survey of alcohol and drug use in Nigeria reported a lifetime, one year and past 30 days alcohol use prevalence as $39.0 \%, 30.3 \%$ and $24.5 \%$ respectively. Past 30-day prevalence rates of other commonly used drugs are solvent /inhalant (3.2\%), Tranquilizer (2.9\%), Opiates other than Heroin (2.2\%), Heroin (1.8\%), Cannabis $(1.8 \%)$, and Cocaine $(1.4 \%){ }^{6}$

The harmful consequences of drug use are associated with psychiatric disorders, medical conditions and physical injuries. ${ }^{7}$ Furthermore, globally, an estimated 183,000 drug-related deaths were reported in 2012, 
corresponding to a mortality rate of 40.0 deaths per million among the population aged $15-64 .{ }^{8}$ Drug use is one of the major causes of mortality among young people in Europe, through overdose and drug-related diseases and accidents, violence and suicide, resulting in excess mortality that is 10 to 20 times greater than expected. ${ }^{9}$ The use of alcohol was significantly associated with risky sexual behavior among a community sample in Lagos, Nigeria. ${ }^{10}$ The use of psychoactive substance accounts for major health care problems frequently leading to emergency department admission, though it is often missed or not diagnosed. ${ }^{11}$

The prevalence of substance use disorders is higher in population treated in healthcare facilities than in the general population, and it is considered to be more prevalent in general emergency services. ${ }^{11}$ In 2011, over 125 million visits were made to emergency departments in general-purpose, non-Federal hospitals operating 24-hour emergency departments in the United States. ${ }^{12}$ Drug Abuse Warning Network (DAWN) estimates that over 5 million of these visits, or about 1,626 emergency department visits per 100,000 populations, were related to drugs, a 100 percent increase since 2004.

In Africa there is scarce information on the problem of patients with substance abuse or dependence attending general emergency units. A study conducted in Egypt on substance abuse and dependence among patients attending an emergency unit, revealed $8 \%$ with substance abuse and $3.5 \%$ with substance dependence. ${ }^{13}$ While in Nigeria, a study conducted among in-patients of medical and surgical wards of a tertiary institution showed prevalence rate for alcohol use disorder as $9.3 \%$ with $1.4 \%$ and $7.9 \%$ for alcohol abuse and dependence respectively. ${ }^{14}$ Another study conducted on injured patients managed in the maxillofacial units of four teaching hospitals in Nigeria among motorcycle riders following accidents revealed that Alcohol and or other substances of abuse were implicated in $31.2 \%$ of the cases. ${ }^{15}$

Studies have shown that the abuse of alcohol may be up to $17 \%$ of the adult population seen at the Primary Healthcare Centers, while in the Emergency Department, the problems related to the consumption of alcohol and drugs may be higher. ${ }^{16,17}$ Lack of awareness and understanding of substance use disorders among service providers and the reluctance of patients to admit their consumption, could be barriers to diagnosis, referral, and treatment in specialized substance abuse units.
Much of the current knowledge of drug-use patterns and trends in Nigeria is, however, based on studies among Secondary School students, University students or Household surveys in Nigeria. ${ }^{18,19,20}$ Relatively little is known about the drug-using patterns of people presenting at hospital accident and emergency departments seeking assistance. This means that there is an important gap in our knowledge about both the prevalence and the nature of drugrelated problems among this segment of the population. Hence, this study provides an important opportunity to gather information from an underresearched population.

\section{Materials and Methods}

This is a cross sectional study conducted at the Jos University Teaching Hospital. The Jos University Teaching Hospital established in 1976 is a 600 bedded Hospital located at Lamingo Jos plateau state of Nigeria, designed to cater for the health needs of communities within the middle belt zone of the country and beyond. In addition, teaching and research in health-related matters are among the services undertaken in the hospital.

The study population comprised of all patients who were 18 years and above presenting at the accident and emergency department of Jos University Teaching Hospital for treatment in the month of June 2016. That is, Patients treated in the emergency room for either medical or surgical cases and were able to give consent. We excluded Patients who were not able to be interviewed due to the nature or severity of their presenting complaint (illness). However patients that were acutely ill and not able to be interviewed at presentation were interviewed after they became stable while still in the emergency room. The minimum sample size required for the study was calculated using the formula below ${ }^{21}$.

$$
\mathrm{n}=\frac{\mathrm{Z}^{2}(1-\mathrm{p}) \mathrm{p}}{\mathrm{d}^{2}}
$$

Where $\mathrm{n}=$ minimum sample size, $\mathrm{z}=$ standard normal variance $=1.96$ at $95 \%$ confidence interval. $\mathrm{d}=$ Absolute standard error $=0.05, \mathrm{p}=$ prevalence

Using a prevalence of $0.115^{13}$ from previous study, an absolute standard error of 0.05 and standard normal variance of 1.96, it was determined that 200 participants will be adequate, calculated using appropriate formula for proportions. 
Following approval from the ethical committee of JUTH and permission to carry out the study from the Head of Accident and Emergency Department of JUTH, consecutive in and out-patients at the accident and emergency unit of JUTH were approached and written consent was obtained after the accident and emergency Doctors had seen and certified them as emergency cases.

The study was conducted in 2 stages. In the first stage a Socio demographic questionnaire was used to obtain information about each patient in combination with emergency room data. A self-report questionnaire was used to obtain more detailed information about the patient's substance use ${ }^{7}$, Alcohol, smoking and substance involvement screening test (ASSIST) questionnaire $^{22}$, which was administered by a trained interviewer to each participant. However, due to literacy status of clients, a Hausa translation was produced in addition to the English version for clients who could not understand English.

In addition, urine samples were taken from each consented patient for a multi-drug screening by immune enzymatic technique. ${ }^{23}$ The following substances were tested: amphetamines (AMP), Methadone(MTD), tramadol (TML), Morphine(MOP), opiates(OPT) 3,4- Methylenedioxymethamphetamines(MDMA),tetrahydrocannabin ol (THC), cocaine (COC), barbiturates (BAR), alcohol (alc), nicotine(nct) and benzodiazepines (BZO). Steps were taken to ensure that drugs detected were not those administered at the Accident and Emergency Unit.

All screened positive respondents from self-report and toxicology test who were 89 in number were entered into the second phase for assessment using the Structured Clinical interview based on the English version of Mini International Neuropsychiatric Interview (MINI) ${ }^{24}$ for the diagnosis of alcohol abuse and dependence and non- alcoholic psychoactive substance abuse and dependence that are based on DSM-IV criteria. ${ }^{25}$ The data collection was conducted every day of the week, in a 24 hour period lasting for a period of two weeks. Some health staffs in the emergency room were trained on the various instruments in which they assisted in administering to patients especially during the night shift.

\section{Data Analysis}

Data was analyzed using Statistical Package of Social Sciences (SPSS) version 16.0. Descriptive statistics such as means and standard deviations were used to summarize continuous variables while categorical variables were summarized with percentages. Chi square test was used to test the significant difference between groups or compare two proportions and to investigate the differences between categorical variables and their association. The student t test was used to compare continuous variables. Statistical significance was set at $<0.05$.

\section{Results}

The socio-demographic characteristics of participants in accident and emergency unit recruited into the study are illustrated in table 1

A total of 200 participants were recruited into the study. Males constituted the majority $111(55.5 \%)$ of the participants compared to $89(44.5 \%)$ of female participants. Participants between ages 21 and 30 years formed the largest $48(24.0 \%)$ age group, while the lowest age group, 18 to 20 was made up of 15 (7.5\%) participants. Majority of the participants 119 (59.5.0\%) were married, $68(34.0 \%)$ were still single while $13(6.5 \%)$ were widowed. Out of the participants $156(78.0 \%)$ were Christians, and 44 (21.5\%) were Muslims.

All the participants were Nigerians 200 (100\%). Hausas were 38 (19.0\%), followed by 31 (15.6\%) participants of berom extraction while 121 (60.5\%) participants were of other ethnicities. In terms of Education; 50(24.5\%) participants had no formal education while $3(1.5 \%)$ participants attended school up to Post graduate level. Most 106 (53.0\%) of the participants were employed while Apprentice 3(1.5\%) constituted the lowest number of participants.

Table 2 Shows Emergency Room Data of the participants recruited into the study, where Seventy nine $(39.5 \%)$ participants were recruited into the study between $6 \mathrm{am}$ to $12 \mathrm{pm}$ while $19(9.5 \%)$ participants were recruited between $12.01 \mathrm{am}$ to $5.59 \mathrm{am}$. One hundred and thirty five $(67.5 \%)$ of the referrals were by self-referrals, while referral by Ambulance i.e. directly from the scene of accident accounted for the least $19(9.5 \%)$ number of participants. Majority of the participants $156(78.0 \%)$ presented with medical illnesses while $44(22.0 \%)$ presented with injury. Among those that presented with medical illness, majority of the participants $151(75.5 \%)$ presented with physical illness while $5(2.5 \%)$ presented with psychiatric illness. 
Table 1: Demographic characteristics of participants

\begin{tabular}{|c|c|c|}
\hline $\begin{array}{l}\text { Demographic } \\
\text { characteristics }\end{array}$ & Frequency(N=200) & $\begin{array}{l}\text { Percentage } \\
(\%)\end{array}$ \\
\hline \multicolumn{3}{|l|}{ Gender } \\
\hline Male & 111 & 55.5 \\
\hline Female & 89 & 44.5 \\
\hline Total & 200 & 100.0 \\
\hline \multicolumn{3}{|l|}{ Age group } \\
\hline$\leq 20$ & 15 & 7.5 \\
\hline $21-30$ & 48 & 24.0 \\
\hline $31-40$ & 42 & 21.0 \\
\hline $41-50$ & 34 & 17.0 \\
\hline $51-60$ & 27 & 13.5 \\
\hline$>60$ & 34 & 17.0 \\
\hline Total & 200 & 100.0 \\
\hline \multicolumn{3}{|l|}{ Marital status } \\
\hline Single & 68 & 34.0 \\
\hline Married & 119 & 59.5 \\
\hline Widowed & 13 & 6.5 \\
\hline Total & 200 & 100.0 \\
\hline \multicolumn{3}{|l|}{ Religion } \\
\hline Christianity & 156 & 78.0 \\
\hline Islam & 44 & 22.0 \\
\hline Total & 200 & 100.0 \\
\hline \multicolumn{3}{|l|}{ Nationality } \\
\hline Nigerian & 200 & 100.0 \\
\hline Total & 200 & 100.0 \\
\hline \multicolumn{3}{|l|}{ Ethnicity } \\
\hline Hausa & 38 & 19.0 \\
\hline Yoruba & 6 & 3.0 \\
\hline Igbo & 4 & 2.0 \\
\hline Berom & 31 & 15.5 \\
\hline Others & 121 & 60.5 \\
\hline Total & 200 & 100.0 \\
\hline \multicolumn{3}{|c|}{ Educational level } \\
\hline Non formal & 50 & 25.0 \\
\hline Secondary & 80 & 40.0 \\
\hline Diploma/NCE & 54 & 27.0 \\
\hline Degree/HND & 13 & 6.5 \\
\hline Postgraduate & 3 & 1.5 \\
\hline Total & 200 & 100.0 \\
\hline \multicolumn{3}{|c|}{ Employment status } \\
\hline Employed & 106 & 53.0 \\
\hline Unemployed & 40 & 20.0 \\
\hline Student & 30 & 15.0 \\
\hline Apprentice & 3 & 1.5 \\
\hline Retiree & 21 & 10.5 \\
\hline Total & 200 & 100.0 \\
\hline
\end{tabular}

Table 3: Shows that the prevalence of substance use disorders among patients presenting at accident and emergency department was $19.0 \% \quad(13.0 \%$ for substance abuse and $6.0 \%$ for substance dependence). Alcohol was the most common drug abused by $7.5 \%$ of patients followed by polysubstance, cannabis and tramadol in $3.0 \%, 1.5 \%$ and $1.0 \%$ of respondents respectively. Polysubstance ranked first in the dependence group in $2.0 \%$ of respondents followed by alcohol with $1.5 \%$, then Cannabis and tobacco with $1.0 \%$ prevalence each while tramadol accounted for $0.5 \%$.

Table 4Shows the comparison of the sociodemographic characteristics of accident and emergency room patients and presence of substance use disorders.

Thirty four (30.6\%) males compared to 4 (4.5\%) females have substance use disorders. The widowed had $5(38.5 \%)$ more substance use disorder compared to singles $6(8.8 \%)$ and the married $27(22.7 \%)$. Thirty six $(23.1 \%)$ participants with substance use disorders were Christians while only $2(4.5 \%)$ of the participants with substance use disorders were Muslims. Out of the participants without substance use disorders $42(95.5 \%)$ were Moslems, while 120 (76.9\%) were Christians.

From the above results, substance use disorders was significantly associated with male gender $(\mathrm{P}<0.001)$, widowed $(\mathrm{P}<0.012)$ and Christian religion $(\mathrm{P}<0.006)$.

Table 2: Presentation to Emergency room

\begin{tabular}{|c|c|c|}
\hline Variables & Frequency $(\mathrm{N}=200)$ & Percentage $(\%)$ \\
\hline \multicolumn{3}{|l|}{ Time of emergency } \\
\hline room visit & 79 & 39.5 \\
\hline $6 \mathrm{am}-12 \mathrm{pm}$ & 65 & 32.5 \\
\hline $12.01 \mathrm{pm}-6 \mathrm{pm}$ & 37 & 18.5 \\
\hline $6.01 \mathrm{pm}-12 \mathrm{am}$ & 19 & 9.5 \\
\hline 12.01am-5.59am & 200 & 100.0 \\
\hline \multicolumn{3}{|l|}{ Total } \\
\hline \multicolumn{3}{|l|}{ Type of medical } \\
\hline complaint & 44 & 22.0 \\
\hline Injury & 156 & 78.0 \\
\hline Illness & 200 & 100.0 \\
\hline \multicolumn{3}{|l|}{ Total } \\
\hline \multicolumn{3}{|l|}{ Reason for visit } \\
\hline RTA & 26 & 13.0 \\
\hline Domestic accident & 5 & 2.5 \\
\hline Violence/aggression & 13 & 6.5 \\
\hline Physical illness & 151 & 75.5 \\
\hline Psychiatric illness & 5 & 2.5 \\
\hline Total & 200 & 100.0 \\
\hline \multicolumn{3}{|l|}{ Referral to emergency } \\
\hline room & 19 & 9.5 \\
\hline By ambulance & 135 & 67.5 \\
\hline Own initiative & 24 & 12.0 \\
\hline Health care personnel & 22 & 11.0 \\
\hline Others & 200 & 100.0 \\
\hline Total & & \\
\hline
\end{tabular}


Table 3: Prevalence of substance use disorders among patients

\begin{tabular}{lccr}
\hline Psychoactive substances & Abuse & Dependence \\
$(\mathrm{N}=200)$ & $\mathrm{N}=200)$ & $\mathrm{N}=200$ \\
\hline Overall & $\mathbf{2 6}(\mathbf{1 3 . 0})$ & $\mathbf{1 2 ( 6 . 0 )}$ & $\mathbf{3 8}(\mathbf{1 9 . 0})$ \\
Tobacco & - & $2(1.0)$ & $2(1.0)$ \\
Alcohol & $15(7.5)$ & $3(1.5)$ & $18(9.0)$ \\
Cannabis & $3(1.5)$ & $2(1.0)$ & $5(2.5)$ \\
Opioids(tramadol) & $2(1.0)$ & $1(0.5)$ & $3(1.5)$ \\
Polysubstance & $6(3.0)$ & $4(2.0)$ & $10(5.0)$ \\
& & & \\
\hline
\end{tabular}

Table 4: Socio-demographic features of participants and presence of substance use disorder $\quad \mathrm{N}=\mathbf{2 0 0}$

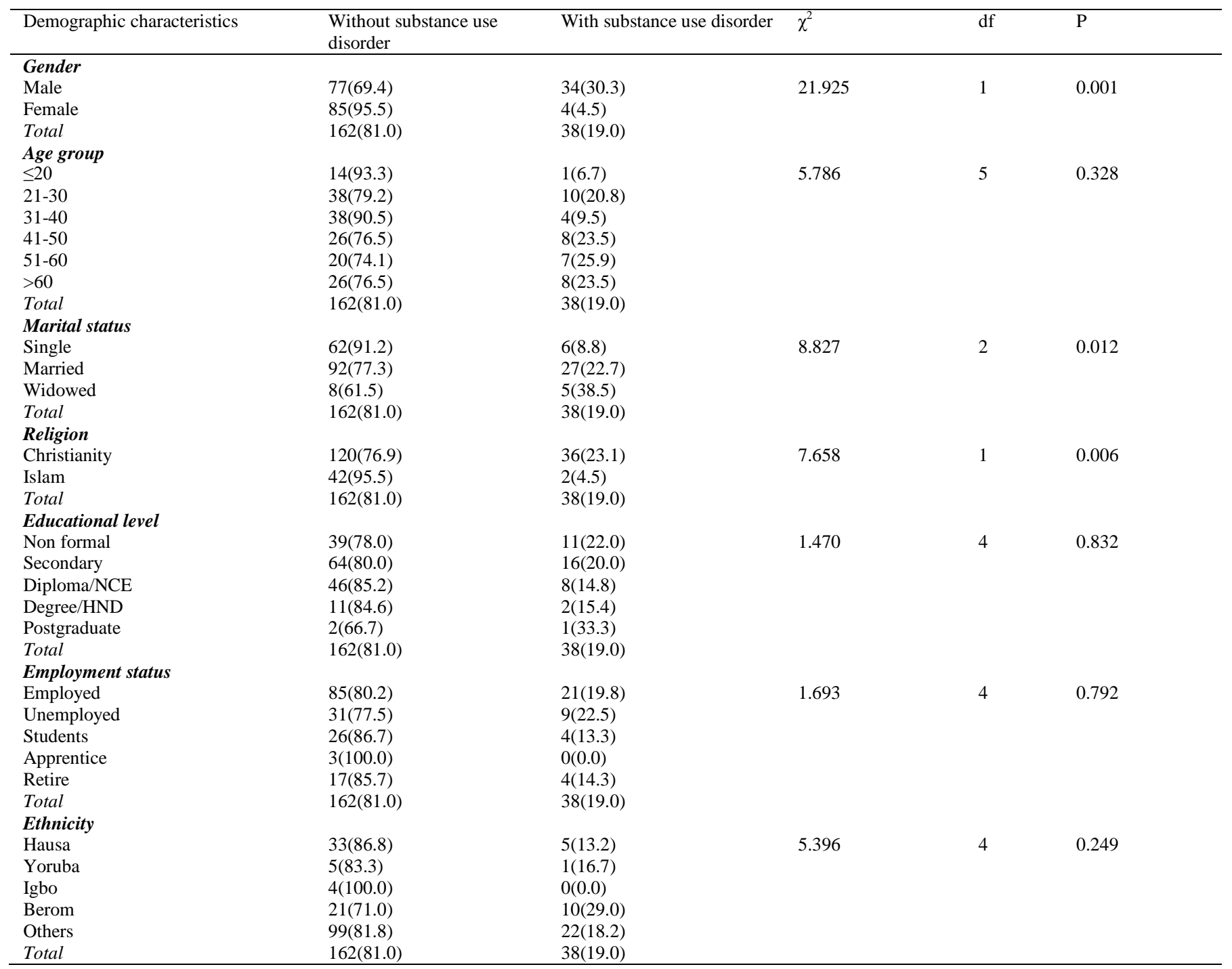

\section{Discussion}

We found that the overall rates for substance abuse and dependence were $13.0 \%$ and $6.0 \%$ respectively. While the prevalence for substance use disorders was $19.0 \%$, alcohol use disorder was more common compared to other drugs. Participants who were male,
Widowed and Christians were more likely to have substance use disorders. The prevalence of substance use disorders in this study is lower compared to the; $54.0 \%$ found by Soderstrom et al. ${ }^{26}$ In that study the apparently higher prevalence might be because the study was conducted among trauma patients only which agrees with some studies that injured patients 
were significantly more likely than medical patients to meet criteria for substance use disorders. ${ }^{27}$ Furthermore their study had larger sample size $(1,118)$ of respondents compared to this study.

On the other hand this study reported a higher prevalence of substance use disorder $19.0 \%$ compared to that reported by Fredric et $\mathrm{al}^{27}(16.0 \%)$, even though they had a larger sample size of 14,557 participants compared to this study. The lower prevalence of substance use disorder in their study might be due to the fact that mid-night shift for data collection was excluded in their study i.e. data collection was only from 9:00am to 11:30pm while in this study, data collection was for 24 hours. It could also be due to different geographical location. Furthermore their study included only ages 19 to 60 while this study included age 18 years and above.

The pattern of substance use disorder found in this study was comparable with similar studies done in other countries. ${ }^{(13,26,27)}$ This study found a higher prevalence of substance abuse of $13.0 \%$ compared to $6.0 \%$ of substance dependence. Among patients with substance abuse, alcohol ranked first $7.5 \%$, followed by polysubstance $3.0 \%$, next was cannabis $1.5 \%$ and tramadol $1.0 \%$. In the dependence group, polysubstance ranked first $2.0 \%$ followed by alcohol $1.5 \%$, then tobacco and cannabis with $1.0 \%$ each, and lastly tramadol with $0.5 \%$. The higher prevalence of substance abuse compared to dependence in this study is attributable to the fact that the use of these psychoactive substances among these participants may not be so severe to meet criteria for dependence.

Similarly, Mustafa et $\mathrm{al}^{13}$ in Egypt recorded a higher prevalence of substance abuse $8.0 \%$ compared to substance dependence $3.5 \%$. Among patients with substance abuse, cannabis ranked first $(3.6 \%)$ then tramadol $1.8 \%$, polysubstance $1.7 \%$, followed by stimulants group $(1.3 \%)$, alcohol $(1.1 \%)$, and finally anticholinergic $(0.5 \%)$ and volatile substances $(0.3 \%)$. In dependence group, tramadol ranked first $(1.2 \%)$ followed by cannabis (1\%) and stimulants $(0.5 \%)$, heroin $(0.37 \%)$, anticholinergic, polysubstance $(0.22 \%)$ and alcohol and volatile substances $(0.07 \%$ each).

In contrast to this study Soderstrom et $\mathrm{al}^{26}$ reported more substance dependence compared to substance abuse in their study among 1118 participants. Substance dependence accounted for $88 \%$ of the $54 \%$ of SUDs reported in their study. This could be due to the fact that their survey was on seriously injured patients only which agrees with some studies that Injured patients were significantly more likely than medical patients to meet criteria for substance use disorders. ${ }^{27}$ The higher prevalence of substance dependence among accident and emergency patients compared to substance abuse could be explained by the fact that people with substance dependence are more likely to have more physical complications or accident due to the severity of the disorder and $\mathrm{it}^{\mathrm{s}}$ associated complications compared to substance abuse leading to emergency presentations.

This study found that the socio-demographic characteristics significantly associated with accident and emergency patients with SUDs are: gender, marital status and religion. Thus accident and emergency patients with SUDs are more likely to be males, widowed and Christians. Acceptance is a key factor for both males and females receiving treatment. Traditionally, drug and alcohol problems are more socially acceptable for males than females. Women who openly use psychoactive substances excessively are seen as not being responsible. ${ }^{28}$ Males are more likely to seek treatment on their own or with the support of their family and friends; conversely, women often get referred for treatment in relation to other problems. This finding is similar to what was reported by leigh et $\mathrm{al}^{29}$ where it was found that most drug related problems are common among males where four out of five respondents were males.

In this study there was significant association between substance use disorder and religion where Christians were diagnosed more with substance use disorders than the Muslims. This is likely the effect of religious permissiveness or prohibition on the use of substances. Islam does not permit the use of alcohol. To most Christians who in some cases are introduced to alcohol ingestion at childhood ${ }^{14}$, alcohol is an important aspect of social events, pleasure, and recreation. Muslims may use drugs they consider not strictly prohibited by religion or which will not attract criticism by other adherents. Gureje et $\mathrm{al}^{30}$ also found that Muslims were much less likely to use alcohol than persons of other faiths, but no such association was found for tobacco, other drugs including cannabis and stimulants both of which are illegal in Nigeria.

Marital status was significantly associated with substance use disorder, where the widowed participants were diagnosed with substance use disorder more than the married and singles. Marriage or being married is considered as the beginning of being responsible in this part of the world, ${ }^{31}$ and the responsibility permeates almost every facet of life. Also, the role of marital status and substance abuse cannot be overlooked because being married may 
have a moderating effect on substance use ${ }^{32}$ possibly due to social integrative function of marriage and the role of social control over risk-taking behavior, and if there is a strain in marriage, it may be as a susceptible factor for abuse. ${ }^{32}$ This view receives support as it was found out that there was more substance dependence amongst individuals who have never married when compared with married, separated/widowed/divorced statuses. ${ }^{32}$

On the contrary this present study showed that the widowed were diagnosed with substance use disorder more than the married, while the married were diagnosed more with substance use disorders than the singles who have never been married. This may be due to the fact that many turn to substances to cope with loneliness when faced with the death of a partner or to cope with depression following the death of a partner. This finding agrees with the study reported by Gureje et al where in their study the married were reported to abuse more psychoactive substances than the singles, even though their study was a household survey. ${ }^{30}$

\section{Conclusion}

The prevalence of substance use disorders recorded in this study is higher compared to previous study conducted by Mustafa et al in Egypt with $11.5 \%$. The reason could be due to inclusion of biochemical test (urine drug test) in our screening, whereas only selfreport questionnaires were used in their study.

\section{Recommendation}

Educational intervention targeted at accident and emergency physicians is required to improve early identification and treatment of substance use disorders among patients presenting at accident and emergency units in Nigeria

Research is needed to develop and test interventions aimed at reducing poly-substance use and increasing substance use treatment entry among this vulnerable population (accident and emergency patients with SUD).

Globally, substance use disorder has become a major public health issue. Therefore, there should be increased consensus, commitment and political will within government to place substance use disorder on the national agenda and secure funding for the disorder.

\section{Limitations}

There were possibilities that substance use disorder was underestimated because of unreliable selfreporting of substance use. On urine drug test, information indicating the quantity, frequency, or time of drug ingestion is limited over the previous few days, with the risk of false-negative and false-positive results. This is a single center hospital based study conducted within two weeks with a small sample size of 200 patients seeking emergency care; its results may not reflect the true situation in the community. Self-report questionnaire was interviewer administered and this could have introduced bias

\section{Conflict of interests}

The Authors declare no conflict of interests.

\section{Reference}

1. Owoaje E.T, Bello J. Psychoactive substance Use among Undergraduate Students of The University of Ibadan, Nigeria. The Tropical Journal of Health Sciences 2010;17(2): 56-60

2. United Nations Office on Drugs and Crime. World Drug Report .Vienna: UNDOC; 2010

3. World Health Organization. Global status Report on Alcohol. Geneva.WHO;2004

4. Abasiubong F, Udobang J.A, Idung A. U, Udoh S.B, Jombo H. E. A Comparative Study of Pattern of Substance Use in Two Nigerian Cities Located in the Southern and Northern Nigeria: An International Multidisciplinary Journal, Ethiopia 2014; Vol. 8 (2),5267

5. Adelekan, M.L, Abiodun, O.A, Obayan, A.O, Oni, G and Ogunremi,O.O. Prevalence and pattern of substance use among undergraduates in a Nigerian University. Drug and Alcohol Dependence 1992; 29:255-261

6. Adamson T, Ogunlesi A, Morakinyo O, Akinhanmi A, Onifade P. Substance abuse in perspective in Nigeria: Report of a national survey on alcohol and use in Nigeria 2012

7. Vitale SG, Van De Mheen D, Van De Wiel A, Garretsen HF. Alcohol and illicit drug use among emergency room patients in the Netherlands. Alcohol, 2006; 41: 553-9

8. World Drug Report. United Nations Office on Drugs and Crime, New York.2014

9. Mena G, Giraudon I, Álvarez E, Corkery JM, Matias J. Cocaine related health emergencies in Europe: a review of sources of information, trends and implications for service development. Eur Addict Res 2013; 19: 74-81 
10. Lawal RA: A Rapid Situation Assessment of Alcohol in Relation to Sexual Behaviors in Lagos, Nigeria. Geneva: World Health Organization 2002

11. Fernando, E.M, Joaquin, N.M, Jose, A.N.V, Fernando, E.F, Detecting Substance Abuse in the Emergency Department: A 10-Year Comparative Study, Hindawi Publishing Corporation ISRN Emergency Medicine, 2013; 10(1):1-7.http://dx.doi.org/10.1155/2013/926749

12. Rockville, M.D. Drug Abuse Warning Network, National Estimates of Drug-Related Emergency Department Visits: 2011. HHS Publication No. (SMA) 2013:13-4760, DAWN Series D-39

13. Mostafa A, Abdel H. E, Ahmed E, Warda F. Substance abuse and dependence among patients attending an emergency hospital in eastern Nile delta, Egypt; Afr J Psychiatry 2014;17:532-537

14. Okonoda, K.M, Audu, M.D, Obindo J.T, James, T.O.Prevalence of alcohol use disorders among medical and surgical in patients at a Teaching Hospital in North Central Nigeria, Jos journal of medicine 2014; 8(2):22-27

15. Oginni F, Ajike S, Obuekwe O, Fasola O. A prospective multicenter study of injury profile, severity and risk factors in 221 motorcycle-injured Nigerian maxillofacial patients;Traffic Inj Prev. 2009; 10(1):705. doi: 10.1080/15389580802496968

16. CalleP. A, Damen .J, De Paepe.P, Monsieurs K.G, Buylaert W.A. A survey on alcohol and illicit drug abuse among emergency department patients, ActaClinica Belgica,2006; 61(4):188-195

17. Espimartinez F, Nieto J, EspiForcen F. Screening for the substance abuse in the emergency room, The American Journal on Addictions,2011; 21: 388-389

18. Adelekan ML, Makanjuola AB, Ndom RJE, Fayeye JO, Adegoke AA, Amusan O. and Idowu, AI. 5Yearly Monitoring of Trends of SubstanceUse among Secondary School Students In Ilorin, Nigeria, 19881998. WestAfrican Journal of Medicine. 2001; 20 (1): 28-36

19. Makanjuola A.B, Daramola TA, Obembe OA. Psychoactive Substance use among medical students in a Nigerian University.World Psychiatry. 2007 b (6): 4850

20. Aina O.F, Olorunshola D.A. Alcohol and substance use portrayals in Nigerian VideoTapes. Ananalysis of 479 films and implication for public Drug Education. International quarterly of Community Health Education 2008;28(1): 63-71

21. Fisher, A.A., Laing, J.E. Stoeckel, J.E., Townsend, J.W. Handbook for the family Planning Operations Research Design. New York: Population council. 1998.

22. WHO-ASSIST. Guidelines for use in primary care.draft version only 2003; 1 september vol. 1

23. Inc EDI. DrugCheck® Dip Drug Test. USA: Express Diagnostics Int'l Inc 2014

24. Narsimha R. Pinninti N.R, Madison H, Musser E, Rissmiller D. MINI International Neuropsychiatric
Schedule: clinical utility and patient acceptance. European Psychiatry 2003; 18: 361-364

25. American Psychiatric Association. Diagnostic and statistical manual of mental disorders-text revision(DSM-IV). $4^{\text {th }} \mathrm{edn}$.

washington,DC,USA:American Psychiatric Association, 2000

26. Soderstrom CA, Smith GS, Dischinger PC, McDuff DR, Hebel JR, Gorelick DA, Kerns TJ, Ho SM, Read KM.Psychoactive substance use disorders among seriously injured trauma center patients. JAMA. 1997;277(22):1769-74

27. Frederic C. B, Maureen A. W, Kristen L. B, Regan L. M, Rebecca M. C, lynn, S.M. et al, Stephen T. C, and Brenda M. B. Alcohol and Drug Use among Patients Presenting to an Inner-city Emergency Department: A Latent Class Analysis AddictBehav. 2011; 36(8): 793-80

28. Cindy M. Out of the Shadows, Women and Addiction: GPSolo Magazine-October/November 2006

29. Leigh K, Paul M, Greg F, Aden F, Jake M. N. Exploring drug use,prevalence and pattern among emergency department patients. Crime and misconduct commission queensland, 2004

30. Gureje O, Degenhardt L, Olley B, Uwakwe R, Udofia O, Wakil A. et al, Adeyemi O, Bohnert KM, Anthony JC.A descriptive epidemiology of substance use and substance use disorders in Nigeria during the early $21 \mathrm{st}$ century. Drug and Alcohol Dependence. 2007; 91(1):19

31. Aroyewum B. A, Adeyemo S. O, Ifeacho I. C. Sociodemographic variables and personality profiles of patients with substance use disorder in a drug abuse treatment facility in Nigeria. Research on Humanities and Social Sciences www.iiste.org 2014; 4(15): 22245766 I

32. Mustapha I. G, Zahraddeen G. H. Socio-Demographic Factors Associated with Psychoactive Substance Use among Commercial Motorcycle Operators in Kano, Nigeria. Open Journal of Psychiatry, 2016; 6, 76-85. 